INVESTIGACIÓN/RESEARCH

Recibido: 05/04/ 2014---Aceptado: 01/06/2014---Publicado: 15/06/2014

Aarón Rodríguez Serrano1: Universidad Europea de Valencia - Escuela de Arquitectura, Departamento de Proyectos Arquitectónicos y Expresión Gráfica.

aron_stauff@hotmail.com

\title{
HOLOCAUSTO, NAZISMO Y VIDEOJUEGOS: ANÁLISIS DE WOLFENSTEIN (RAVEN SOFTWARE, 2009)
}

\section{RESUMEN}

En el presente trabajo pretendemos realizar una serie de reflexiones introductorias sobre las conexiones entre videojuego, nazismo y holocausto. Para ello, hemos elegido como objeto de estudio el último título de la saga Wolfenstein (Raven Software, 2009), sobre el que aplicaremos una metodología de análisis mixta (elementos técnicos, estéticos, narratológicos y socioculturales). En la primera parte del estudio realizaremos una lectura crítica metodológica de distintos modelos recientes aplicables al análisis de videojuegos. Posteriormente, realizaremos la aproximación a nuestro objeto mediante una división en la que entran en diálogo los elementos específicos del videojuego (sus características de control, los apartados gráfico y sonoro) con sus herencias de las teorías clásicas del relato (estudio narratológico de trama y personaje). Finalmente, en el último apartado del artículo, encaramos la problemática histórica que atraviesa a un videojuego que se vale de sucesos históricos concretos mediante una óptica de descontextualización puramente postmoderna. Para ello, nos valdremos además de una breve contextualización de los videojuegos que han encarado, desde distintas perspectivas, la problemática de la II Guerra Mundial.

\section{PALABRAS CLAVE}

Videojuego - Nazismo - Análisis - Wolfenstein - Holocausto - Segunda Guerra Mundial - Estética - Postmodernidad - Representación

\footnotetext{
1 Aarón Rodríguez Serrano: Profesor Titular de la Universidad Europea de Valencia, Máster en Historia y Estética de la Cinematografía (Universidad de Valladolid), Máster en Nuevas Tendencias y Procesos de Innovación en Comunicación (Universitat Jaume I - Castellón). Miembro de la Asociación Española de Historiadores del Cine y de la Asociación Trama\&Fondo.
} 


\title{
HOLOCAUST, NAZISM AND VIDEOGAMES: ANALYSE OF WOLFENSTEIN (RAVEN SOFTWARE, 2009)
}

\begin{abstract}
In the current research we will try to propose some introductory notions about the connections between videogames, nazism and Holocaust. In order to achive that goal, we have chosen as our object the last chapter of the Wolfenstein's saga (Raven Software, 2009). We will apply a complex analyse technique who combines technical, aesthetical, narratological and socio-cultural techniques. In the first part of our paper we will realize a brief recapitulation of some different methodologies in the analysis of videogames. After that, we will propose a complex reflexion about the specific videogame language (control characteristics, interface, the graphic and sound construction...) and the connections with the classical theory of narration (plot and character). Finally, in the last epigraph, we will face the historical problematic, understanding our videogame as a text who is connected with concrete historical debates, and at the same time, with the postmodern way of creating universes. We will include a brief classification of the several videogames who had touched the Nazism issues during the last decades.
\end{abstract}

\section{KEY WORDS}

Nazism - Videogames - Holocaust - Wolfenstein - Analysis - Postmodernity Aesthetics - Representation - World War II

\section{INTRODUCCIÓN}

En 1921, después de un encierro casi monacal en una cabaña de Noruega, el filósofo Ludwig Wittgenstein publicó un libro que cambiaría para siempre el mundo del pensamiento, el Tractatus Lógico-Philosophicus (2009). Entre otros méritos, aquel escueto ejemplar compuesto de peligrosos aforismos que cabía en la palma de la mano, había clarificado para siempre el límite del lenguaje, su trampa, su imposibilidad de resolver cualquier enigma que no perteneciera al universo de la ciencia. Y, por ende, había reducido la ciencia a una parodia de sí misma, un conjunto de datos gélidos sobre lo real que, a decir del aforismo 5.43: “Todas las preposiciones de la lógica dicen lo mismo. Es decir, nada".

La cita a Wittgenstein podría interpretarse gratuitamente si no fuera porque, apenas un par de décadas después, las cámaras de filmación de los aliados entraron en el laberinto sin fondo de los campos de concentración y de exterminio. Wittgenstein había escrito el núcleo duro del Tractatus -los puntos 3, 4, 5 y 6- en las trincheras de la Primera Guerra Mundial, en un ambiente de locura, desesperación y caos que sin duda armonizaba demasiado bien con el paraje intelectual del soldado austríaco. En un parpadeo, sus tesis habían emergido, se habían encarnado en lo real y se cifraban en las montañas de cadáveres que una pala metálica arrojaba a las fosas comunes de Bergen Belsen. Las cámaras, como decimos, estuvieron allí para dar testimonio. 
Videojuego - Nazismo - Análisis - Wolfenstein - Holocausto - Segunda Guerra

Mundial - Estética - Postmodernidad - Representación

De ahí, el problema de la representación audiovisual del Holocausto y del nazismo ha sido el principal campo de batalla ético en el que, desde bien entrados los sesenta, se han ido cruzando propios y extraños. Por un lado, y principalmente representados por los supervivientes, una serie de teorías iconoclastas conducidas por, entre otros, Primo Levi (2012) o Ellie Wiesel (2008), se han ceñido con fuerza a los postulados de Wittgenstein y han peleado la irrepresentabilidad de Auschwitz, su inefabilidad, el vacío total, el agujero negro para el lenguaje (no sólo audiovisual, sino también historiográfico). Más adelante, Claude Lanzmann (2003 y 2011) acabará erigiéndose como el representante último de esta corriente, en parte -y contradictoriamente- por su propuesta documental Shoah (1985), y en parte también por su más que conocida intransigencia ante manifestaciones holocáusticas netamente postmodernas como $\mathrm{La}$ lista de Schindler (Schinder's List, Steven Spielberg, 1993) o la polémica novela Las benévolas (Littell, 2012).

En oposición a los iconoclastas, se ha desarrollado en paralelo una línea que defiende la capacidad de representación audiovisual del Holocausto que tiene como mayores exponentes a los filósofos franceses Georges Didi-Huberman (2004) y Jacques Rancière (2011), aunque también podríamos situar en paralelo distintas declaraciones del director Jean-Luc Godard, las tesis del historiador marxista Pier Paolo Poggio (2006), e incluso algunas aportaciones españolas recientes (Rodríguez Serrano, 2012 y 2013).

Curiosamente, el papel del videojuego ha sido poco o nada estudiado en estos debates. En primer lugar, probablemente se trate de un efecto colateral sobre la lentitud que ha experimentado el videojuego para ser considerado un objeto de estudio serio, a la altura de otras representaciones audiovisuales típicamente postmodernas como el cine-ensayo o el ensayo multimedia. La relación entre videojuego y nazismo parece -al menos, desde una óptica tradicional- ya manchada de una cierta banalización, un cierto componente incómodo que se atraviesa en el pensamiento mismo. ¿Cómo se podría jugar el nazismo? ¿Se trata de una aberración moral, una traición histórica, un divertimento pornográfico? O por el contrario, ¿se pueden utilizar las capacidades educativas del videojuego para (re)construir la Historia?

Para intentar responder -aunque sea tangencialmente- a estas preguntas, proponemos la aplicación sistemática de una metodología de análisis textual específica del videojuego al objeto Wolfenstein (Raven Software, 2009), tanto por su particular lectura del nazismo en términos postmodernos como por la amplia penetración del mismo en la comunidad de videojugadores -como atestiguan sus adaptaciones para XBOX360, Playstation 3 y PC.

\section{OBJETIVOS}

Los objetivos del presente artículo pueden ser sintetizados de la siguiente manera:

a. Proponer una breve síntesis crítica del material bibliográfico relacionado con el análisis de videojuegos y su pertinencia a la hora de aplicarlo a un objeto de 
estudio como Wolfenstein.

b. Realizar una aproximación analítica a la experiencia del videojugador en dicho producto centrada en los siguientes aspectos:

a. Elementos técnicos y de accesibilidad (Hardware, elementos de control).

b. Elementos de construcción estética (Apartado gráfico y sonoro).

c. Elementos narratológicos (Estructura narrativa, construcción de personaje, referentes literarios)

d. Elementos experienciales (Curvas de aprendizaje, niveles de dificultad)

e. Elementos socio-culturales (Límites de acceso, perfil del jugador)

f. Elementos de contexto histórico (el videojuego como arte postmoderno, así como antecedentes de otros juegos que hayan encarado la II Guerra Mundial o el contexto holocáustico).

\section{METODOLOGÍA}

El videojuego, por definición, complica notablemente los márgenes clásicos en los que se movía el análisis textual de inspiración más o menos semiótica. En primer lugar, el componente de interactividad que configura la presencia de un videojugador anónimo hace que ciertos lugares comunes -la pasividad, la ausencia de respuesta crítica, la alienación del receptor- deban ser puestos en duda, aunque sea puntualmente. El videojuego funciona en torno a estímulos físicos, generalmente caracterizados por la velocidad, la inmediatez y la carga instintual. En el caso concreto de Wolfenstein, esto parece ser radicalmente más importante debido al género al que pertenece -un shoot'em'up en primera persona. La supervivencia del videojugador depende exclusivamente de su capacidad para reaccionar físicamente ante el reto planteado por la máquina. De hecho, pese a que el argumento está convenientemente punteado por distintos puzles -tendremos ocasión de referirnos a esto más adelante- su complejidad intelectual es prácticamente mínima, limitándose a localizar un interruptor alejado que abre una puerta determinada, o a utilizar en algún lugar concreto alguno de los poderes del "velo" para poder acceder a una zona oculta o para localizar un punto débil en alguno de los enemigos finales.

Para encarar correctamente el análisis, hemos decidido utilizar una metodología mixta que combina el sistema desarrollado por el Dr. Emilio Sáez Soro (2013), intentando complementarlo con algunas lecturas al respecto que nos han parecido especialmente estimulantes. Afortunadamente, hemos encontrado una discreta pero muy práctica bibliografía previa que nos ha permitido clarificar algunos puntos o nos ha dotado de alguna herramienta especialmente útil. Así, por ejemplo, el trabajo Playing Research: Methodological approaches to game analysis de Espen Aarseth (2004) traza una interesante clasificación que, sin ser demasiado novedosa, propone una estructura clara que apoya una lectura transversal del videojuego, incluyendo consideraciones técnicas -diseño de sonido y diseño visual, programación, modelado...- que puedan redondearse con aportaciones de tipo narratológico, económico, y por supuesto, sociológico. Especialmente interesante nos resulta su división tripartita sobre los elementos que configuran la experiencia virtual, 
Videojuego - Nazismo - Análisis - Wolfenstein - Holocausto - Segunda Guerra

Mundial - Estética - Postmodernidad - Representación

divididos en:

- Gameplay (las acciones que toma el jugador, sus estrategias y sus motivaciones)

- Game-Structure (Las normas que marcan su experiencia, incluyendo aquellas que tienen que ver con la simulación)

- Game-World (El contenido de ficción, el diseño topográfico de los distintos niveles, las texturas...)

El trabajo de Aarseth, pese a ser interesante a nivel introductorio, falla a la hora de intentar proponer una hipotética "hermenéutica del videojuego", intentando generar una herramienta no demasiado comprensible -y cuya traducción exacta se nos antoja prácticamente imposible: "The hermeneutic feed-back loops of play and non-play" (2004: 5).

Nuestro trabajo también se muestra deudor de un estudio de caso concreto, el artículo que Lars Konzack (2002) propuso como análisis monográfico de Soul Calibur y que tituló Computer Game Criticism: A Method for Computer Game Analysis. La propuesta de Konzack también se nos antoja excesivamente simple en lo que a sus intenciones intelectuales o de lectura textual se refiere, si bien destaca notablemente en lo concerniente a claridad expositiva y concisión estructural. Así, Konzack propone una estructura de análisis focalizada en las siguientes "etiquetas" (layers) que son brevemente desarrolladas: Hardware, Program Code, Functionality (término que engloba distintas referencias relacionadas con la programación y la relación de interactividad entre usuario y videojuego), Gameplay (categoría general que engloba tanto el uso del espacio y del tiempo como las normas de interactividad que deben seguirse en el transcurso narrativo del juego), Meaning (una suerte de categoría general sin concretar que apunta a posibles lecturas sociológicas y narrativas), Referentiality (relaciones cruzadas e hipertextuales que insertan el videojuego en un contexto superior) y, finalmente, Socio-Culture.

Mucho más estimulante nos ha supuesto la lectura de dos trabajos monográficos de gran envergadura destinados en exclusiva al análisis de videojuegos. El primero es la tesis doctoral $A$ behavioural analysis of computer game playing competence, experience and related psychological processes, presentada por el doctorando Conor Linehan (2008). Al tratarse de una investigación de largo recorrido, podemos observar cómo el autor realiza un auténtico esfuerzo por compatibilizar las teorías del behaviourismo (o de un cierto constructivismo social) con la experiencia del videojugador. Concretamente, su diseño de investigación propone una serie de experimentos en torno a conceptos como la jugabilidad o la recepción con respecto al género. Lamentablemente, Linehan no nos aporta herramientas específicas para analizar detenidamente un shooter en primera persona como es Wolfenstein, pero sí que se permite el lujo de analizar, de manera muy breve, el funcionamiento de un producto cercano, el Doom 3. Las claves de su éxito -fácilmente aplicables, por otro lado a Wolfenstein- son, según el autor, la Ficción, la Meta y lo que denomina "Agency": 
Por ejemplo, en Doom 3, el jugador es un marine de los Estados Unidos atrapado en una estación científica cercana a Marte. La meta hace referencia al objetivo concreto que dispara el deseo de jugar una partida. En Doom 3, la meta sería permanecer vivo y avanzar hacia la siguiente localización de la estación científica. "Agency" [término intraducible] se refiere al mecanismo por el que se puede conseguir esa meta. En el ejemplo de Doom 3, la "Agency" se refiere a la acción de armarse y disparar contra los monstruos mientras se transitan los distintos niveles (2008: 2).

Más allá del behaviourismo y desde una perspectiva puramente semiótica, el trabajo más sólido que hemos consultado es el complejo análisis de Tomb Raider 2 propuesto por Patrick Sunnen bajo el título Making Sense of Video Games: A Textual Analysis of Tomb Raider 2 (2000). El mayor logro de Sunnen -y sin duda, el gran hallazgo para encarar nuestro estudio- ha sido su capacidad para aplicar las teorías tradicionales del relato ya presentes en Propp (1998) o las técnicas de análisis textual de sabor barthesiano a la lectura narratológica concreta de un videojuego. Debemos reseñar que el trabajo no esconde en ningún momento sus propios límites, y es capaz de encarar con una enorme altura problemáticas conectadas con la perspectiva de género, la mixtura de géneros postmoderna, y por supuesto, las posibilidades educativas de los videojuegos.

Especialmente guiados por la rúbrica de este último trabajo y de su estimulante contenido intelectual, procedemos a encarar el análisis concreto de la experiencia del videojugador que se pone a los mandos de Wolfenstein. Para ello, dividiremos nuestro trabajo en tres secciones principales: Elementos técnicos, en la que trabajaremos los problemas derivados del hardware y el control, una segunda relacionada con el Concepto de juego, en la que incorporaremos las cuestiones narratológicas y una tercera de Elementos socio-culturales.

\section{ANÁLISIS Y DISCUSIÓN}

\subsection{Elementos técnicos}

\subsubsection{Hardware y sistemas de control}

Para analizar Wolfenstein hemos manejado dos versiones distintas: la correspondiente a PC y su equivalente para XBOX 360. Dicho ejercicio ha sido especialmente interesante para comparar tanto los aspectos gráficos como la jugabilidad que se puede extraer de ambas versiones. Llama la atención, en primer lugar, que el tránsito de plataformas sea un calco prácticamente exacto: misma traducción, misma estructura, mismos modos multijugador. Ciertamente, no nos sentimos demasiado seguros a la hora de señalar una superioridad gráfica por parte de la versión de consola, si bien en nuestra experiencia, la XBOX ha mostrado mejores rendimientos tanto en los tiempos de carga de las distintas zonas como en las prestaciones visuales ofrecidas. La experiencia de jugar en un monitor de PC de gama media frente a una televisión capaz de soportar la Alta Definición de la consola de Microsoft, obviamente, hace que optemos por esta segunda posibilidad. 
Videojuego - Nazismo - Análisis - Wolfenstein - Holocausto - Segunda Guerra

Mundial - Estética - Postmodernidad - Representación

De igual manera, hemos podido experimentar la diferencia entre jugar con teclado/ratón y pad. En el caso de Wolfenstein, la configuración de juego es prácticamente igual a cualquier otro shooter contemporáneo con el que se pueda comparar: movimiento del personaje asociado al teclado y punto de vista y disparo referentes al ratón. Esta manera de moverse realmente por un entorno 3D popularizada a raíz de los primeros escenarios completamente tridimensionales de Quake (Id Studio, 1996) se sigue manteniendo prácticamente inalterable, y el estudio desarrollador de Wolfenstein -Raven Software- no ha realizado ninguna modificación notable. Sin duda, esto supone un punto fuerte para el jugador acostumbrado a los shooters, ya que el interfaz resulta conocido y amigable, no requiriendo ningún tipo de aprendizaje previo. Los parámetros básicos de comportamiento del jugador correr, saltar, recargar, disparar- son absolutamente automáticos e intuitivos. En cuanto a la experiencia de controlar Wolfenstein con un pad, se repite también el mismo contacto intuitivo y fácilmente manejable. En esta ocasión, los dos joysticks sustituyen los controles de movimiento y punto de vista, siendo quizá ligeramente más complicado recargar y acceder a los menús de juego.

\subsubsection{Interfaz específico}

De entrada, la simplicidad de Wolfenstein parece no hacer necesaria la introducción de un interfaz especialmente complicado. Frente a títulos anteriores de la saga, en esta ocasión se ha preferido remarcar la integración y utilizar un único elemento circular situado en la esquina inferior derecha de la pantalla y en el que el jugador encuentra a simple golpe de vista la información que necesita. Básicamente, los dos datos que debe manejar un sujeto para la supervivencia tienen que ver con los recursos de munición -tipo de arma que se lleva activada, munición de la misma, estado del cargador- y los recursos mágicos o "del velo" -tipo de poderes que se pueden activar, cantidad de magia que queda disponible para ser activada. Con esos dos parámetros básicos se pueden controlar con facilidad las posibilidades de éxito en una emboscada o frente a un convoy hostil, de tal manera que el jugador puede optar por enfrentarse al enemigo o desandar los pasos para buscar recargas.

En segundo lugar, Wolfenstein incorpora una pequeña brújula en la parte superior central de la pantalla para favorecer la orientación del videojugador. Pese a su simplicidad, podemos reseñar su verdadera utilidad a la hora de poder ir encarando las distintas misiones. Cada marcador responde a una misión principal o secundaria -según se encuentre activada en el diario del personaje-, y también se puede controlar si el objetivo se encuentra en un punto de vista superior o inferior con respecto al plano físico en el que se encuentra el avatar. Concretamente, en esta edición de la saga Wolfenstein esta herramienta se hace absolutamente necesaria, ya que los escenarios "base" -concretamente, el pequeño pueblo en el que se sitúa una parte importante de la acción y que sirve como conexión con distintos niveles adyacentes- suelen ser bastante complejos e intrincados.

En esta dirección, Wolfenstein nos permite también acceder a un mapa bastante simple en el que podemos encontrar marcados los puntos clave del desarrollo de la 
partida: acceso a misiones principales y secundarias, lugar en el que se encuentra algún personaje con el que debamos interactuar... Ciertamente, el mapa parece hacer un flaco favor a los propios desarrolladores de Raven Software, ya que su estudio acaba señalando las carencias del mapeado y la marcada linealidad de la acción. Por poner un ejemplo concreto, cuando nos desplazamos de un lugar a otro del pueblo acompañados por algún miembro de la Resistencia, un simple vistazo al mapa nos permite intuir dónde se encontrarán las barricadas nazis. Sin embargo, no hay posibilidad alguna de atajar o burlar al enemigo, de tal manera que finalmente la única posibilidad es transitar todos los espacios -las plazas, los callejones...- hasta llegar al punto de activación de la siguiente misión.

Del mismo modo, en algunos momentos concretos del juego -al terminar cada una de las misiones, pero también al interactuar con algunos vendedores afiliados a la Resistencia-, se despliega una de las pantallas más importantes de la propuesta: la que da pie a la compra de mejoras para las armas. Como veremos más adelante, Wolfenstein permite una cierta autonomía en la manera en la que cada jugador decide afrontar el desarrollo de la aventura: bien desde un rol más marcado de "francotirador", derribando a los blancos a distancia, bien fortaleciendo el enfrentamiento cara a cara mediante ametralladoras o lanzallamas. La experiencia de juego nos lleva, inevitablemente, a comprar aquellas mejoras que realmente consideremos más urgentes. El interfaz con el que se realizan estas transacciones es más que correcto, mostrando tanto el precio como una breve descripción de cada una -mejora del pulso, ampliación del cargador, aumento de la distancia de disparo...

Por último, en todo momento se puede consultar un interfaz que nos permite acceder a los controles básicos del juego: salvar y cargar la partida, modificar los parámetros gráficos o los controles...

\subsubsection{Diseño gráfico}

Desde la primera entrega de la saga - Wolfenstein 3D (Id Software, 1992), absolutamente todas las entregas, expansiones, versiones y secuelas han utilizado la relación entre tridimensionalidad y punto de vista como una marca identitaria. De los rudimentarios pasillos decorados por texturas pixeladas tras la que se intuía el retrato de Hitler hasta la cuidada iluminación en interiores de la versión que nos ocupa se puede trazar una línea que recorre toda la Historia reciente de los shooters en primera persona.

El diseño gráfico de Wolfenstein es el heredero directo de la tradición cinematográfica. En primer lugar, merece la pena señalar que no hay ningún tipo de ejercicio mínimo de reconstrucción histórica que intente convertir al producto en verosímil: no se cita ninguna ciudad concreta, ningún héroe de la resistencia o ningún episodio bélico específico. Esto, generará dos efectos opuestos. Por un lado, negará la posibilidad de que el videojugador se familiarice con los eventos de la II Guerra Mundial -o, digámoslo en toda su crudeza, que la experiencia de juego tenga el más mínimo efecto educativo-, pero a su vez permite confeccionar un apartado visual 
Videojuego - Nazismo - Análisis - Wolfenstein - Holocausto - Segunda Guerra

Mundial - Estética - Postmodernidad - Representación

vertiginosamente postmoderno y libre. La experiencia gráfica dispara un inquietante cortocircuito simbólico entre lo reconocido (la figura de Hitler, los uniformes de las SS) y lo puramente ficcional.

Otra cuestión bien diferente tiene que ver con el diseño de los últimos niveles de juego. A medida que Blazkowicz se va internando en los secretos mistéricos del Sol Negro y sus territorios sobrenaturales, podemos apreciar un notable cambio tanto en la construcción icónica como en la manera de entender la iluminación. En primer lugar, el aire kitsch entre el nazismo descarado y el (dudoso) encanto tirolés se va convirtiendo en escenarios cada vez más sombríos, muchos de ellos descaradamente surrealistas -por ejemplo, los saltos temporales a los universos arrasados en la brecha interdimensional-, más cercanos al género de la ciencia ficción que a la hipotética reconstrucción histórica. En segundo lugar, podemos apreciar cómo si bien las primeras misiones tienden a desarrollarse a plena luz del día, según avanza el juego, la iluminación tiende a simular esa suerte de noche alienígena de la que emergen los enemigos y que rodea las últimas localizaciones.

Otra cuestión que nos gustaría desarrollar en este apartado son las distintas escenas cinemáticas que sirven como puente para hacer avanzar la historia, así como introducir o cerrar las misiones. Ciertamente, al igual que ocurre con los propios elementos "jugables". Curiosamente, la construcción de las imágenes es sorprendentemente clásica, utilizando en general planos medios y americanos montados con una lógica convencional, que parece remitir a los rasgos del Modo de Representación Institucional, y con una lógica de montaje absolutamente narrativa.

En cierto sentido, hemos entendido las cinemáticas como cumplidos y modestos homenajes a ese género de Serie B propagandístico típico del bando de los Aliados durante la II Guerra Mundial. Su construcción icónica remite constantemente a un enfrentamiento de folletín cuajada de tópicos en la que todo se reduce a una simple confrontación maniquea entre el bien y el mal. Tendremos ocasión de retomar esta idea posteriormente, cuando analicemos la construcción narrativa.

\subsubsection{Ambientación musical}

La partitura original que el compositor Bill Brown propone para el videojuego se compone, en general, de piezas orquestales de corta duración que se apoyan principalmente en las secciones de cuerda y en las secciones de viento. Se trata de una referencia, de nuevo cinematográfica, a toda esa línea de sonoridad bélica que atraviesa la época de los grandes estudios. Concretamente, nos atreveríamos a señalar dos referentes inmediatos de la música de Wolfenstein en los que hemos detectado una textura sonora similar: la partitura que Franz Waxman generó para El espiritu de San Luis (The Spirit of St. Louis, Billy Wilder, 1957), que también se apoyaba en crescendos de cuerda y metal, y el trabajo de Alfred Newman para El diablo de las aguas turbias (Hell and High Water, Samuel Fuller, 1954), especialmente en el prólogo con el que se abría la película.

La música de Wolfenstein, sin embargo, no tiene los toques exóticos de Newman ni las 
deudas contraídas con la ópera de un, pongamos por caso, Miklós Rózsa. Del mismo modo, huye de la melodía fácil y reconocible, trabajando en su lugar sobre la sugerencia y el cuidado del grave. Por ejemplo, si analizamos Main Theme -la melodía que acompaña en el menú principal y cada vez que se pausa el juego-, veremos que durante los primeros treinta segundos apenas podemos localizar una serie de cuerdas que se arrastran sugerentemente. Ni siquiera los tres platillos que puntean las frases melódicas -y tras los que debería estallar el crescendo- parecen conducir la pieza a ningún lado. Antes bien, Brown prefiere sugerir un estado de tensión antes que explicitarlo.

Podemos encontrar otro ejemplo similar en SafeHouse BM, en la que una serie de notas largas de cuerda están levemente punteadas por lo que parece un arpa, hasta que a lo lejos se sugieren una serie de redobles que remiten a las marchas de los nazis. La música en ningún momento se impone, sino que construye una textura sonora que sirve para vestir los momentos de transición entre combate y combate.

Otro ejemplo bien distinto son las músicas que Brown compone específicamente para ser escuchadas durante el combate. Entre ellas, destaca especialmente Church Combat Despoiled, en la que el compositor abandona las referencias a Waxman para lanzarse directamente a un tipo de composición épica que remite de manera explícita a la obra reciente de Hans Zimmer. Así, tras un golpe de viento cacofónico, se despliegan una serie de acuerdas sin una armonía concreta sobre las que se impondrá un contundente patrón rítmico de percusión -nueva referencia a las marchas militares nazis-, y antes de la mitad del tema, un coro masculino que marca una melodía entre la salmodia y el himno militar. En esta ocasión, Brown dejará que la música crezca y crezca dando mayor protagonismo al coro durante la segunda parte del tema hasta acabar en un agudo atonal de cuerdas. Obviamente, este tipo de melodías son las que realmente convierten la experiencia de batalla en algo espectacular.

La música en Wolfenstein es principalmente extradiegética -emitida por el enunciador total del videojuego-, y se utiliza casi siempre en dos momentos concretos: antes del combate para generar una cierta tensión previa y en aquellos momentos narrativos en los que la batalla alcanza sus máximas proporciones.

\subsection{Concepto de juego}

\subsubsection{Estructura narratológica}

El análisis narrativo de Wolfenstein es razonablemente simple. En primer lugar, se puede detectar una línea principal compuesta por diez fases cuyo recorrido es obligatorio y que deben resolverse de manera lineal. En paralelo, se desarrollan una serie de misiones secundarias de dificultad variable que el jugador puede recorrer si así lo desea.

La motivación principal que llevaría al videojugador a optar por las misiones secundarias -y aumentar, por lo tanto, la vida útil del juego- tendría que ver con la 
Videojuego - Nazismo - Análisis - Wolfenstein - Holocausto - Segunda Guerra

Mundial - Estética - Postmodernidad - Representación

adquisición de mejoras para las armas que le permitieran encarar con más comodidad los niveles más elevados. También podrían recorrerse en busca de logros escondidos. Sin embargo, no aportan una mejora sustancial: ni mejoras en el uso del velo, ni armas extra, ni tampoco una serie de matices narrativos realmente relevantes.

Cada fase se abre y se cierra con una secuencia cinemática que en ningún caso dura más allá de los dos minutos. Se trata de píldoras narrativas breves que, como comentábamos en las páginas anteriores, beben de una iconografía directamente inspirada en las películas localizadas en la II Guerra Mundial. Más concretamente, nos gustaría matizar que el sabor de dichas secuencias es puramente postmoderno, ya que la mezcla de elementos históricos y paranormales parece apuntar, antes que a nada, a la construcción icónica de la saga Indiana Jones. Del mismo modo, y contradiciendo las normas clásicas de las estructura aristotélica narrativa y sus aplicaciones audiovisuales, el cierre del relato no aporta ningún tipo de información relevante ni "premia" lo suficiente al videojugador con alguna filigrana visual. Wolfenstein, simplemente, termina con una sucesión de explosiones y apenas unos segundos del Agente Blazkowicz escapando del universo paralelo. Los créditos se ofrecen con un poco inspirado roll que ni siquiera tiene su propio tema musical de cierre.

En esta dirección, Wolfenstein es un juego marcadamente lineal, que no ofrece prácticamente ningún margen al videojugador para que pueda modificar de ninguna manera ni la propia Historia ni su tránsito de la misma. Si bien es cierto que se permite un cierto nivel de interactuación con el entorno -paredes que se atraviesan, ventanas que estallan, trazados que se modifican levemente-, la lógica parece conectada con el shooter original en el que el avatar se limita a ir recorriendo uno tras otro una serie de espacios en un marcado orden inamovible. Con esta misma orientación, debemos señalar que cada uno de los niveles sólo tiene una única solución posible. No hay "trayectos alternativos" para alcanzar las metas, ni distintas maneras de solucionar los puzles o las emboscadas: de hecho, la propia topografía de los escenarios -que se componen, antes que nada, de pasadizos estrechos o pasillos angostos salpicados de barricadas tras las que parapetarse- parece beneficiar este tipo de soluciones: Blazkowicz avanza mecánicamente -y nosotros con él- en busca del enemigo final, recorriendo un único camino. Esta imposibilidad de generar una topografía abierta tiene que ver con el propio concepto de Historia cerrada, de Relato único: un único espacio, un único desarrollo narrativo.

\subsubsection{Análisis del personaje principal: El agente Blazkowicz}

Cualquier jugador que haya seguido con cierto interés la saga Wolfenstein -de la que no tardaremos en hablar-, puede reconocer al agente Blazkowicz. Curiosamente, ha ido involucionando, pasando de ser uno de los personajes más carismáticos del mundo del shooter a una suerte de borrón narrativo que se apoya en la nostalgia del videojugador. Desarrollemos esta idea.

Una de las más rutilantes novedades del ya citado Wolfenstein 3D original recordemos, hablamos del año 1992- fue precisamente la presencia del rostro de 
Blazkowicz en el interfaz del juego. Ese truco de "introducir" el rostro dentro del propio universo extradiegético -concretamente, en la barra inferior del interfazgeneraba una extraña dualidad cognitiva en la recepción del personaje. Por un lado, el juego generaba un espejismo de inmersión total incorporando ese punto de vista en primera persona -si bien es cierto que este tipo de mecanismos ya se habían utilizado anteriormente-, y por otro generaba una escisión en la recepción del videojugador al colocar el rostro en el interfaz. Se trataba de un personaje escindido entre su propia identidad y el control del videojugador, escisión que se manifestaba además en tiempo real, simultáneamente. Por ejemplo, cada vez que los nazis o sus perros guardianes herían al avatar por una mala decisión del jugador, veíamos cómo el rostro emitía un rictus de dolor e incluso sangraba.

Sin duda, aquello era de un nivel de inmersión que hoy se nos antojaría humilde y quizá un poco sonrojante. Sin embargo, en su contexto histórico, no dejaba de resultar sorprendente. El shooter en primera persona tendría, bajo nuestro punto de vista, ciertas dificultades en aquella época para dotar a sus personajes del mismo carisma que tenían las estrellas de los otros juegos. ¿Quién era, después de todo, el soldado protagonista de Doom (Id Software, 1993)? ¿Y el héroe de Dark Forces (Lucas Arts, 1995)? Todavía quedaban algunos años para la revolución total -quizá todavía no superada- que supuso el auge y caída de Duke Nukem (Duke Nukem 3D, 3D Realms, 1998), el avatar más carismático de los shooter en primera persona.

El problema, por supuesto, es el siguiente. Una vez que se inicia el reinicio de la franquicia Wolfenstein con Return to Castle of Wolfenstein (Activision, 2001), ya no es posible seguir manteniendo aquel viejo avatar sin apenas personalidad. Los shooter, tanto en primera como en tercera persona, han demostrado que pueden construirse con personajes complejos y de gran riqueza narrativa -pensemos, por ejemplo, en Max Payne o la propia Lara Croft-, exigiendo curvas de transformación, impulsos contradictorios, profundidad narrativa. Lamentablemente, para los creadores de las secuelas, el centro de la acción ha sido considerado una suerte de significante total esto es, vacío- que responde únicamente al apellido Blazkowicz sin ofrecer nada más.

En el juego sólo podemos ocupar su lugar, y por ende, no optaremos a ningún tipo de evolución física o psicológica. Se trata, de nuevo, de una contradicción con la experiencia histórica de la II Guerra Mundial, ya que elementos que configuran las narrativas habituales como el trauma o el descubrimiento -la anagnórisis aristotélica aplicada a la experiencia demoledora del nazismo- son simplemente dejados aparte de la ecuación narrativa.

\subsubsection{Inspiración pagana}

Como hemos señalado en varias ocasiones a lo largo del trabajo, Wolfenstein está narrativamente construido en torno a una lógica postmoderna que combina elementos del serial bélico de Serie B con elementos de ciencia ficción. En esta dirección, se conecta explícitamente escrita su deuda tanto con la sci fi de bajo presupuesto de los años cincuenta como con la mitología de H. P. Lovecraft (2011) y todos sus herederos. 
Videojuego - Nazismo - Análisis - Wolfenstein - Holocausto - Segunda Guerra

Mundial - Estética - Postmodernidad - Representación

Sin embargo, el hecho de que Wolfenstein se apoye explícitamente en un contexto histórico acotado bien merece una sucinta consideración. En primer lugar, es necesario recordar que toda la panoplia supersticiosa y de sabor pseudomístico ya estaba presente en la propia historia del III Reich (Lesta, 2005). Las fuentes de su fascinación son razonablemente sencillas de rastrear: por un lado, Hitler construyó la eficacia simbólica de sus huestes homicidas en torno a ritos de iniciación en los que la influencia de las sagas nórdicas y la mitología tradicional pagana alemana aparece a cada paso. Así, por ejemplo, la constante mención a la épica romántica que encuentra su mayor encarnación cultural en las óperas de Richard Wagner -compositor que fascinaba a Hitler casi hasta el delirio (Hegner, 1967)- se conecta con otros mitos convenientemente adaptados al desquiciante tejido ritual del III Reich: camaradería en iniciaciones rituales en la montaña mezcladas con infructuosas búsquedas de la Atlántida o del Santo Grial puntean los libros sobre la Alemania nazi compartiendo capítulos con los retratos de los campos de exterminio o los métodos brutales de las SS.

La saga Wolfenstein, por su parte, siempre ha sido muy consciente de esta "deriva mísitca" del III Reich y la ha utilizado a su favor para construir tramas más o menos interesantes, dejando de lado ese aspecto de "reconstrucción" o de "simulación" histórica que aparece en sagas paralelas como Call of duty. Antes bien, su construcción en el género pende más de la tradición que conecta la ucronía literaria con la II Guerra Mundial (K. Dick, 2002) que con una investigación tradicional al uso. Todo Wolfenstein parte de la base de que los delirios pagano-místicos del III Reich pudieron ser ciertos.

\subsubsection{Curva de Aprendizaje y Nivel de dificultad}

Ahora bien, ¿cómo se traduce todo lo anterior en términos de experiencia del videojugador? En cierto sentido, Wolfenstein es un juego que está notablemente bien construido en lo que a nivel de dificultad y curva de aprendizaje se refiere. En primer lugar, y aunque parezca una notable contradicción, uno de los puntos fuertes del juego en términos de jugabilidad es su simplicidad. Lo único que Wolfenstein realmente ofrece es adrenalina pura y dura. El placer de ir apretando el gatillo mientras se avanza, resolviendo puzles de dificultad mínima. Todo el funcionamiento narrativo tiene que ver con "desconectar" y utilizar únicamente los reflejos de camino al final de la fase. El armamento y el número de enemigos suele estar bien nivelado, así como el número de impactos que puede recibir el personaje antes de morir. Las fuentes de munición, así como las fuentes para "recargar el velo" -extraños sumideros de color azulado sobre los que nuestro personaje descansa unos segundos- suelen ser localizables sin demasiada complicación y se distribuyen de manera inteligente en el diseño de los escenarios, de tal modo que muchas veces, cuando nos encontramos con una emboscada especialmente complicada, lo único que debemos hacer es volver sobre nuestros pasos, recargar lo que sea necesario y avanzar hasta aniquilar al grupo de enemigos de turno. Del mismo modo, la Inteligencia Artificial de los enemigos, sin ser ninguna maravilla, funciona a la perfección para combinar algunos objetivos fácilmente abatibles -por ejemplo, 
enemigos que dejan sus posiciones a cubierto para abalanzarse de manera más o menos suicida contra el protagonista- y personajes parapetados cuya eliminación puede resultar un auténtico suplicio.

En segundo lugar, los escenarios son razonablemente diferentes entre sí, por lo que se pueden recorrer de misión a misión sin llegar a acabar especialmente hastiado. Bien es cierto que no hay una gran diversidad de localizaciones, pero la combinación de interiores y exteriores, días y noches, pueblos y castillos, lugares abiertos y cerrados, ofrece una más que agradable topografía para recorrer.

En tercer lugar, en cuanto al nivel de dificultad, no podemos afirmar que Wolfenstein sea un juego especialmente difícil. La curva de dificultad y aprendizaje evoluciona de manera casi imperceptible pero constante. No hay grandes desniveles que puedan desmotivar al videojugador, sino que todo está correctamente nivelado para que la evolución se realice de manera continua e intuitiva.

\subsection{Elementos socioculturales}

\subsubsection{Límites de acceso al juego y perfil del jugador}

La lectura de sociocultural de Wolfenstein es de una inmensa complejidad, y ha sido sin duda lo que más nos ha interesado a la hora de trabajar este videojuego. En primer lugar, en este momento y con el sistema de calificación por edades, nos parecería estúpido empezar la casa por el tejado y realizar la habitual perorata sobre la hipotética violencia del producto, siendo además un tema sobradamente estudiado en otros lugares (Díez Gutiérrez, 2005; De Miguel, 2006; Etxebarría, 2011). Wolfenstein es un shooter de tradición fantástica, y como tal, se basa en la aniquilación como fuente principal de goce. Remite a la construcción heroica tradicional en las narrativas occidentales (Sánchez-Escalonilla, 2002), y por lo tanto, responde a la lógica de que un cierto de tipo de violencia más o menos apocalíptica (en este caso, representada en el régimen nazi) sólo puede ser combatida mediante el uso de una violencia similar generada en su contra.

Dicho esto, si no se comparte la premisa básica sobre la que se sustenta el producto, jamás se podrá estar de acuerdo con su contenido o con la serie de experiencias que plantea. No hay ningún elemento educativo en su interior ni se pretende extraer ninguna lección útil sobre la vida, ningún dogma, ninguna revelación. A partir de aquí, todo discurso que se quiera levantar corre el riesgo de ser extraordinariamente paratextual y puede funcionar como una suerte de añadido desconcertante a lo que está dentro del propio videojuego. No hay ningún tipo de contenido dentro del texto que fomente las habilidades de inteligencia emocional, sino que al contrario, el videojugador se convierte en estímulo puro sin ningún tipo de barniz ético o de transferencia emocional con el relato o sus actantes. En esta misma dirección, es lógico que el juego deba disfrutarse a partir de una cierta edad, principalmente por dos problemas básicos. El primero es el constante flujo de elementos puramente estimulantes (disparos, muertes, explosiones) que pueden generar una cierta 
Videojuego - Nazismo - Análisis - Wolfenstein - Holocausto - Segunda Guerra

Mundial - Estética - Postmodernidad - Representación

ansiedad tras una exposición descontrolada. El segundo, y no menos interesante, es que Wolfenstein se toma ciertas licencias más que notables con la verdad histórica que requieren un cierto conocimiento previo. Por mucho que, como comentábamos hace unas páginas, toda la parafernalia pseudomísitca ya estuviera presente en el III Reich, la verdad histórica que hay tras el nazismo, sus consecuencias y su importancia histórica está mínimamente tratada en el interior del videojuego. Es por esto que su hipotético valor educativo es, como señalábamos, prácticamente inexistente.

\subsubsection{Apuntes socioculturales: videojuegos, nazismo, postmodernidad.}

Por definición, el videojuego emerge como un producto artístico puramente postmoderno. No sólo por el contexto histórico en el que alcanza su mayor apogeo, sino por su íntima relación con los debates filosóficos derivados de la crisis de la modernidad. Nos referimos, concretamente, a los problemas de la escisión del sujeto y la erosión del yo. El videojuego genera los viejos sueños románticos del XIX pensamos, concretamente, en los autómatas de Hoffmann (2006) - para acabar formando parte de aquello que el tándem Deleuze/Guattari llamaron, no sin cierta sorna desesperada, "las máquinas deseantes" (1985).

Dicho con otras palabras: los videojuegos entablan una relación íntima nunca antes soñada entre el relato y el videojugador. Relación intensa de deseo, que funciona a dos niveles: un nivel puramente literario -el jugador recorre un relato, se somete a una narración, generalmente legible desde los parámetros más o menos convencionales de la teoría de la literatura comparada- y un nivel específicamente físico -cualquier videojugador sabe que el nivel de concentración y la respuesta corporal emitida es indudablemente más intensa en una buena partida que en la lectura de una novela o incluso, en la recepción de la inmensa mayoría de las películas.

La clave, a nuestro entender, es la inmersión del videojugador. Lo que, dicho sea de paso, en la saga Wolfenstein nos llevará directamente de cabeza al problema nuclear de nuestro trabajo: las posibilidades de la representación y los extraños nexos personales entre jugador y avatar, así como las complicaciones éticas que surgen de su encuentro. El videojuego, al tratarse, como decíamos, de un producto necesariamente postmoderno, no puede hacerse cargo de la herencia del pasado si no es por la vía del pastiche, la reformulación irónica o el kitsch.

El videojuego es el producto afterpop (Fernández Porta, 2010) por definición, ese espacio textual en el que la Historia ya sólo se reconoce como cita, como torsión. Por mucho que haya una serie de videojuegos que intenten recoger, con mayor o menor fortuna y coherencia, los restos de un pasado lejano -pensamos en la saga Civlization de Sid Meier-, en la inmensa mayoría de productos que recordamos haber jugado en los últimos años, la Historia se utiliza únicamente como una suerte de marco simbólico que opera para dar un contexto espacial e icónico al juego que resulte fácilmente reconocible por el usuario. De hecho, el mantenimiento imposible de "la Historia" acaba convirtiéndose en una rueda imposible de "las historias", siendo lo más común encontrarse de pronto con, pongamos por caso, un dinosaurio en mitad 
de la saga Tomb Raider o las aventuras romanas y medievales de Duke Nukem en Time to kill (N-space, 1998). El carácter necesariamente abierto del videojuego -ese carácter que promete una secuela detrás de otra, una ampliación, una nueva vuelta de tuerca- contradice la realidad histórica, cronológica, cerrada, de la Historia en su sentido clásico tradicional. En esta dirección, el videojuego está más cerca del culebrón neobarroco tal y cómo lo entendía Omar Calabrese (2012), siempre valiéndose de una cronología afortunadamente disparatada (esto es, postmoderna) que se expande hacia el infinito.

Probablemente, el mejor texto escrito hasta la fecha sobre la problemática que nos ocupa -la conexión entre nazismo, holocausto y videojuegos- es el muy estimulante Ephemeral Games: Is it barbaric to design videogames after Auschwitz?, redactado por el diseñador y fundador de Ludology.org Gonzalo Frasca (2000). El planteamiento del autor pasa por hacer una reflexión que parte de la famosa frase de Adorno sobre la pertinencia de escribir poesía después de Auschwitz para enfrentarse con la seriedad y las connotaciones éticas de ciertas temáticas aplicadas a los videojuegos. Como el propio autor afirma:

Nuestra cultura tiene una serie de elementos con los que no se puede jugar (forbidden games). Los niños aprenden que que hay cosas que no están diseñadas para jugar con ellas (...) La situación en el mundo de los videojuegos es todavía más complicada, porque combinan el miedo a la representación (por ejemplo, "La exposición a contenido violento puede generar conductas violentas") con el miedo a la empatía (por ejemplo, "actuar de manera violenta en entornos simulados sigue siendo actuar de manera violenta") (2000:173-174).

Ya no nos enfrentamos con el viejo problema de la cultura iconoclasta -la cultura que, irónicamente, todavía arrastra la herencia judía con su correspondiente prohibición a la representación-, sino que además nos enfrentamos con una cultura normativa aterrada ante las variables de la interacción y la participación. Si, siguiendo las teorías de Foucault (1978), la cultura tiene un serio problema a la hora de actuar para escribir sus normas sobre los cuerpos violentos, los cuerpos que optan -fuera de los propios límites del sistema a comportarse violentamente (como en el caso del propio nazismo, que alentaba y premiaba un uso político de la violencia)-, durante los últimos años los videojuegos nos han llevado todavía más lejos al proponer la existencia de cuerpos que se comportan de manera violenta... en un entorno virtual.

La saga Wolfenstein, desde su primer título se ha situado en un territorio histórico fangoso. Ciertamente, es de rigor señalar que la suya nunca ha sido, ni remotamente, una voluntad de hipotética reconstrucción histórica. No hay nada -o casi nada- en los juegos que parezca remitir, de manera coherente y verosímil, a la verdadera historia del III Reich. De hecho, la primera sensación que nos transmite la saga es que se vale de la potencia simbólica e icónica del nazismo para dotar a sus juegos de una línea visual entre la polémica y la cita fílmica. De hecho, los nazis que emergen en las primeras entregas de la saga -así como las propias tramas narrativas- parecen más 
Videojuego - Nazismo - Análisis - Wolfenstein - Holocausto - Segunda Guerra

Mundial - Estética - Postmodernidad - Representación

deudoras de la primera construcción spielbergiana y postmoderna del nazismo que de la propia realidad histórica. Así, podríamos estar más cerca de los nazis que aparecían, por ejemplo, en aquella exquisita aventura gráfica en la que LucasArts adaptó, con todo de lujo de detalles, la película Indiana Jones y la última cruzada.

Hay, en todo caso, algunos detalles sobre los que merece la pena detenerse. A diferencia de los distintos productos firmados al alimán por Lucas y Spielberg, en los primeros Wolfenstein hay citas más o menos explícitas de la realidad holocáustica. Así, por ejemplo, entre los enemigos que asolan al héroe, se pueden localizar perros de la misma raza que los utilizados por los SS en las llegadas de los trenes al campo de Auschwitz-Birkenau. Del mismo modo, el propio castillo de Wolfenstein que da nombre al título remite, de manera más o menos consciente, a todas esas fortalezas europeas que se reutilizaron para convertirse en centros de detención, tortura y asesinato. De hecho, hay una suerte de inquietante reconocimiento en el visitante que pasea por Mauthaussen al encontrarse, en el diseño de las puertas, la tipografía, los colores de la piedras, el tipo de estructura que los nazis utilizaron para instalar su máquina de muerte, exactamente el mismo tipo de construcción icónica que aparecerá en, por ejemplo, Return to castle of Wolfenstein.

\subsubsection{Antecedentes en el tratamiento de la II Guerra Mundial en el mundo del videojuego.}

La saga Wolfenstein no fue, en cualquier caso, el primer acercamiento de la industria del videojuego a la Segunda Guerra Mundial. Por ejemplo, en una fecha tan temprana como 1985 -siete años de que saliera a la calle Wolfenstein 3D, el primer título de la saga- ya nos encontramos con Silent Service, un simulador de lo ocurrido en Pearl Harbour firmado por el ya citado Sid Meier. Diseñado con unos precarios gráficos en 8-bits que corrían en los AMSTRAD CPC o los ZX Spectrum de la época, Silent Service nos invitaba a sumarnos al bando aliado en su lucha en el Pacífico. Un primer dato interesante es que, al consultar las reseñas publicadas en el momento de su lanzamiento ${ }^{2}$, ningún crítico pareció mostrar sorpresa alguna ante la localización histórica de la contienda. Antes bien, se señalaron otros datos como la jugabilidad o la facilidad del manejo.

Además del campo concreto de la estrategia, durante la década de los ochenta se estrenaron Conqueror (Superior Software, 1988), un simulador de tanques en el que por primera vez se nos invitaba a tomar parte del bando alemán si así lo deseábamos. Dicho con toda crudeza, el videojugador podía convertirse literalmente en un soldado nazi ${ }^{3}$. Del mismo modo, y especialmente relevante para nuestro estudio

2 Puede encontrarse una selección completa en la siguiente dirección web: http://www.ysrnry.co.uk/articles/silentservice.htm [Consultado el 18 de Febrero de 2014].

\footnotetext{
${ }^{3}$ Apenas unos años después, los desarrolladores japoneses General Support siguieron el ejemplo con la salida al mercado de Koutetsu no Kishi (1991), un juego de tanques en el que únicamente se podía manejar al ejército alemán y, consecuentemente, perder la guerra tras la Batalla de Moscú. Desde luego, no resulta fácil entender
} 
supuso el lanzamiento de The Great Escape (Ocean Software, 1986), un juego diseñado mediante perspectiva isométrica en el que por primera vez se incorporaba el campo de concentración como espacio en el que se desarrollaba el juego de manera explícita. La mecánica de la producción de Ocean era terriblemente sencilla: se trataba de vivir como un interno entre alambradas, observando minuciosamente las rutinas de los SS hasta conseguir ejecutar un plan de fuga. De nuevo, debemos reseñar que la prensa especializada del momento no se paró en hacer ninguna valoración ética del contenido del videojuego, sazonando sus críticas de halagos como el siguiente:

The Great Scape [sic] no deja de ofrecernos sorpresa tras sorpresa. Se trata de un programa que hay que irlo [sic] descubriendo poco a poco para llegar a encontrar todas las posibilidades que nos puede presentar (...) The Great Scape [sic] es una de las mejores videoaventuras que se han hecho para un Spectrum. Y que conste que a esta frase le hemos puesto el plural porque no nos gusta ser absolutistas. (Artículo sin firmar, 1987: 25)

Estas declaraciones, además de confirmarnos lo mucho que ha avanzado -estilística y gramaticalmente- la crítica de videojuegos en los últimos años, nos demuestran cómo para la prensa del momento no era posible establecer una reflexión sobre las posibilidades históricas o los dobleces humanísticos de un videojuego. Sin embargo, la construcción icónica del programa estaba clara: alambradas, torres de vigilancia, barracones con literas... La disposición del escenario, de hecho, mostraba un alarmante parecido con algunos campos diseñados específicamente en torno a la idea de observación del prisionero como Sachsenhausen.

\section{CONCLUSIONES}

A lo largo de las presentes páginas hemos intentado esbozar un análisis somero e impresionista de un producto cultural especialmente complejo. Como el lector habrá podido detectar, es inevitable no experimentar una tensión entre los contenidos técnicos y específicamente propios de la experiencia del videojugador (el análisis de los mecanismos que nos permiten interactuar con el mundo, las características estéticas que lo conforman y que son, a su vez, herederas de un imaginario icónico postmoderno muy reciente), con aquellas implicaciones éticas y socioculturales que nos salen al paso a la hora de trabajar videojuegos conectados explícitamente con el nazismo.

Del mismo modo, se habrá podido comprobar que en lugar de intentar suavizar o integrar dicha brecha, nuestra apuesta analítica ha sido justamente la contraria: ponerla de manifiesto mediante una escisión explícita entre contenidos estéticos e implicaciones históricas, sin establecer nunca una línea moral normativa sobre cómo deben ser juzgadas y pensadas esas imágenes interactivas. La justificación de esta decisión -que podría ser interpretada, sin duda, como una carencia- parte de una serie de decisiones referentes tanto al estado actual de la cuestión -que

el punto de vista del videojuego, máxime cuando se supone que uno de los alicientes del videojugador debe ser ganar la batalla y no perderla. 
Videojuego - Nazismo - Análisis - Wolfenstein - Holocausto - Segunda Guerra

Mundial - Estética - Postmodernidad - Representación

cartografiábamos brevemente en la introducción- como a características propias de la investigación presentada. Nuestro interés no era generar una adición argumentativa al eterno debate entre iconoclastas e iconódulos, sino simplemente introducir que las viejas torsiones sobre representación y holocausto deberán abrirse pronto a otras características como la comunicación en redes sociales (Rodríguez Serrano, 2011), la transmisión de memoria gracias a las nuevas tecnologías móviles, y por supuesto, los videojuegos.

Nos gustaría, por lo tanto, que la presente aportación fuera considerada simplemente como la primera intución en un campo de estudio innovador y novedoso, tan urgente por sus connotaciones éticas como todavía poco trabajado. Nos hemos valido de herramientas analíticas todavía florecientes y quizá demasiado deudoras del análisis crítico tradicional que las revistas divulgativas llevan generando durante más de treinta años, y sin embargo, sus ventajas para generar una somera cartografía de la experiencia del sujeto que juega son innegables: permiten transitar tanto las características de interactuación física como el propio placer de tránsito narratológico que acompaña a los buenos relatos.

Hay, no obstante, una idea sugerida en el trabajo ya citado del filósofo Jacques Rancière (2011) que creemos que puede ser un buen colofón a propósito de nuestra búsqueda y nuestras expectativas de cara al futuro. El autor francés afirma que los debates entre representación e inefabilidad tienen lugar dentro de un contexto pautado, un régimen ideológico estricto que marca las fronteras entre lo representable y lo que debe ser ocultado a la mirada. No hay nada, dicho de otra manera, que atraviese el texto en sí mismo y que sea moralmente indudable. Si esta sugerencia resulta ser cierta, entonces no hay más que configurar el videojuego -tal y cómo nosotros hemos comenzado a hacerlo aquí- como un régimen mismo de representación, anclado en un flujo imaginario colectivo concreto (la postmodernidad) y atravesado por tensiones estéticas y éticas que responden a nuestra manera de comprender el mundo. Su relación con lo mostrable del horror o con la capacidad de interactuar con la vivencia de los campos, por chocante que nos parezca, fue ya asumida desde sus primeras propuestas a finales de los ochenta. Ahora el reto se encuentra, sin duda, en saber encarar el magma textual que encierra cada experiencia lúdica para ver si se trata de un diálogo con la Historia, o como hemos mostrado en el caso de Wolfenstein, un simple saqueo de rastros del pasado.

\section{REFERENCIAS}

Aarseth, E. (2004). Playing Research: Methodological approaches to game analysis. En AAVV (2004), Actas del I Congreso Spilforskning. Recuperado de http://www.bendevane.com/VTA2012/herrstubbz/wpcontent/uploads/2012/01/02.GameApproaches2.pdf Consultado el 17/02/2014.

Artículo sin firmar (1987). La gran evasión. En Revista MicroHobby, No 106, p. 25.

Calabrese, O. (2012). La era neobarroca. Madrid: Cátedra. 
De Miguel, R. (2006). Cuestiones en torno al poderoso efecto de los videojuegos violentos. En Revista Icono 14. Vol. 4.

Deleuze, G. y Guattari, F. (1985). El antiedipo: Capitalismo y esquizofrenia. Barcelona: Paidós.

Didi-Huberman, G. (2004). Imágenes pese a todo: Memoria visual del Holocausto. Barcelona: Paidós.

Díez Gutiérrez, E. (2005). Violencia y videojuegos. En Revista Crítica. No 55, pps. 6568.

Etxebarría, F. (2011). Videojuegos violentos y agresividad. En Pedagogía Social: Revista interuniversitaria. $\mathrm{N}^{\mathrm{o}} 18$, pps. 31-39.

Fernández Porta, E. (2010). Afterpop: La literatura de la implosión mediática. Barcelona: Anagrama.

Foucault, M. (1978). Vigilar y castigar. Nacimiento de la prisión. México: Siglo XXI Editores.

Frasca, G. (2000). Ephemeral Games: Is it barbaric to design videogames after Auschwitz? En Revista CyberText. No 1, pps. 172-182.

Hegner, H. S. (1967). El Tercer Reich. Ascensión y caída del Régimen Nazi. Barcelona: Plaza \& Janés.

Hoffmann, E. T.A. (2006). Cuentos 1 y 2. Barcelona: Editorial Alianza.

K. Dick, P. (2002). El hombre en el castillo. Barcelona: Minotauro.

Levi, P. (2012). Trilogía de Auschwitz: Si esto es un hombre / La Tregua/ Los hundidos y los salvados. Madrid: El Aleph.

Lanzmann, C. (2003). Shoah. Madrid: Arena Libros.

Lanzmann, C. (2011). La liebre de la Patagonia. Barcelona: Seix Barral.

Lesta, J. (2005). Las claves esotéricas del III Reich: Nazis, magia y ocultismo. Madrid: Edaf.

Linehan, C. (2008). A behavioural analysis of computer game playing competence, experience and related psychological processes (Tesis inédita de doctorado). National University of Ireland.

Littell, J. (2012). Las benévolas. Madrid: Editorial RBA. 
Videojuego - Nazismo - Análisis - Wolfenstein - Holocausto - Segunda Guerra

Mundial - Estética - Postmodernidad - Representación

Lovecraft, H. P. (2011). Narrativa Completa. Madrid: Valdemar.

Konzack, L. (2002). Computer Game Criticism: A Method for Computer Game Analysis. En AAVV (2002), Actas del congreso "Proceedings of computer games and digital cultures". Tempere: Aarhus University.

Poggio, P. P. (2006). Nazismo y revisionismo histórico. Madrid: Akal.

Propp, V. (1998). Morfología del cuento. Madrid: Akal.

Rancière, J. (2011). El destino de las imágenes. Pontevedra: Editorial Politopías.

Rodríguez Serrano, A. (2011). Nuevas formas audiovisuales de la representación del Holocausto. Lenguajes postmodernos para la reconstrucción de la memoria. En Revista Prisma Social. No 6, pps. 1-22.

Rodríguez Serrano, A. (2012). Nuevas perspectivas teóricas sobre las representaciones fílmicas del Holocausto: Análisis textual sobre el rol del testigo de tercer grado como protagonista. En AAVV (2012), Actas del IV Congreso Internacional Latina de Comunicación. Recuperado de http://www.revistalatinacs.org/12SLCS/2012_actas/081_Rodriguez.pdf Consultado el 17/02/2014.

Rodríguez Serrano, A. (2013). La muerte que habla. La escritura del Holocausto en La zona gris. En Revista Trama \& Fondo. No 35, pp. 103-116.

Sáez Soro, Em. (2013). Homo viodeoludens 2.0. De Pacman a la gamificación. Barcelona: Laboratori de Mitjans Interactius.

Sánchez-Escalonilla, A. (2002). Guión de aventura y forja del héroe. Madrid: Ariel.

Sunnen, P. (2000). Making Sense of Videogames: A Textual Analysis of Tomb Raider 2 (Tesis inédita de doctorado). University of London.

Wiesel, E. (2008). Trilogía de la noche: La noche/El alba/El día. Madrid: El Aleph.

Wittgenstein, L. (2009). Tractatus Logico-Philosophicus. Barcelona: Editorial Alianza. 